\title{
Distribution of Usutu Virus in Germany and Its Effect on Breeding Bird Populations
}

\author{
Renke Lühken, Hanna Jöst, Daniel Cadar, Stephanie Margarete Thomas, Stefan Bosch, \\ Egbert Tannich, Norbert Becker, Ute Ziegler, Lars Lachmann, Jonas Schmidt-Chanasit
}

\begin{abstract}
Usutu virus (USUV) is an emerging mosquitoborne flavivirus with an increasing number of reports from several countries in Europe, where USUV infection has caused high avian mortality rates. However, 20 years after the first observed outbreak of USUV in Europe, there is still no reliable assessment of the large-scale impact of USUV outbreaks on bird populations. In this study, we identified the areas suitable for USUV circulation in Germany and analyzed the effects of USUV on breeding bird populations. We calculated the USUVassociated additional decline of common blackbird (Turdus merula) populations as $15.7 \%$ inside USUV-suitable areas but found no significant effect for the other 14 common bird species investigated. Our results show that the emergence of USUV is a further threat for birds in Europe and that the large-scale impact on population levels, at least for common blackbirds, must be considered.
\end{abstract}

U sutu virus (USUV) is a mosquitoborne flavivirus that, together with West Nile virus (WNV), belongs to the Japanese encephalitis antigenic complex (1). Both viruses share a similar enzootic transmission cycle, with birds as amplifying hosts and ornithophilic mosquitoes as vectors (2). Mammals, including bats, horses, and humans, are considered incidental or dead-end hosts (3-6).

The clinical picture of human USUV infection includes fever, rash, jaundice, headache, nuchal rigidity,

Author affiliations: Bernhard Nocht Institute for Tropical Medicine, World Health Organization Collaborating Centre for Arbovirus and Hemorrhagic Fever Reference and Research, Hamburg, Germany (R. Lühken, H. Jöst, D. Cadar, E. Tannich, J. Schmidt-Chanasit); German Centre for Infection Research (DZIF), partner site Hamburg-Luebeck-Borstel, Hamburg (H. Jöst, E. Tannich, J. Schmidt-Chanasit); University of Bayreuth, Bayreuth, Germany (S.M. Thomas); Nature and Biodiversity Conservation Union (NABU), Stuttgart, Germany

(S. Bosch); Institute for Dipterology, Speyer, Germany (N. Becker); University of Heidelberg, Heidelberg, Germany (N. Becker); Institute of Novel and Emerging Infectious Diseases, GreifswaldInsel Riems, Germany (U. Ziegler); Nature and Biodiversity Conservation Union (NABU), Berlin, Germany (L. Lachmann)

DOI: https://doi.org/10.3201/eid2312.171257 hand tremor, and hyperreflexia (7). It has been generally assumed that the incidence of human USUV infections is very low compared with the incidence of WNV infections. However, this assumption is probably strongly biased by the comparatively low capacity to correctly identify USUV infection in humans $(2,8)$. Recent data from Italy indicate that human USUV infections may not be a sporadic event and can even be more frequent than WNV infections in areas where both viruses co-circulate (9).

The most common recent ancestor of the USUV strains circulating in Europe emerged in Africa at least 500 years ago (10). In 1996, the first recognized USUV outbreak outside Africa caused a massive die-off among common blackbirds (Turdus merula) in the Tuscany region of Italy (11). During the next 2 decades, USUV was observed in several countries in Europe as responsible for periodic small epizootic outbreaks affecting birds $(2,12)$. In Germany, the earliest observation of USUV was in 2010 in mosquitoes (13) and resulted in mass deaths of common blackbirds $(12,14)$ and at least 2 human USUV infections $(4,6)$.

Mosquitoborne pathogens such as WNV (15) or avian malaria (16) could have substantial negative effects on bird populations, such as the size of affected populations (15) or composition of species communities (16). Several bird taxa of different taxonomic orders were found to be susceptible to USUV infections (2); during the USUV outbreaks in Europe, common blackbirds accounted for the largest proportion of observed dead birds (2). The effect of USUV on the populations of this species is discussed in different studies, which gave different estimates for population declines. Savini et al. (17) estimated 1,000 deaths for blackbirds in Veneto, Italy, in 2008-2009. During the USUV outbreak in Vienna, Austria, and surrounding areas in 2003-2005, Steiner and Holzer (18) observed a population decline of $\approx 90 \%$. Furthermore, Rubel et al. (19) estimated that only $0.2 \%$ of all dead blackbirds were detected by the national USUV monitoring program in Austria (20), and therefore, $\approx 50,000$ birds died during the outbreak. Using the same method of estimation, $\approx 40,000$ common blackbirds died in the earliest known outbreak 
(2011-2012) in Germany (21). Further studies in Germany estimated 220,000-420,000 dead common blackbirds (22) and a local population reduction of $>50 \%$ (23).

The existing studies lack 2 conditions: an explicit spatial distinction between areas in which USUV circulates and those in which it does not; and the analysis of longterm bird population data, which are necessary to test the hypotheses that USUV caused substantial population declines in birds. Therefore, 20 years after the first observed outbreak of USUV in Europe (11), a reliable assessment of the large-scale impact of USUV outbreaks on bird populations is missing. Identifying the populationlevel effects of the disease is challenging, because they must be distinguished from natural population fluctuations driven by environmental factors such as climate (15) or land use change (24). Thus, the analyses require longterm bird abundance data that extend before and after the emergence of the disease and that cover areas with and without circulation of the pathogen. Hence, the aims of this study were the identification of areas suitable for USUV circulation in Germany using a distribution modeling approach based on dead bird surveillance data and the comparative analysis of USUV effects on the breeding bird populations in USUV-suitable areas.

\section{Materials and Methods}

\section{Distribution Modeling Data}

The USUV data in Germany were collected as part of a dead bird surveillance program $(12,14,25,26)$. After the description of a USUV outbreak in wild birds in Germany in 2011, we requested, by press releases and media dissemination, that citizens send dead birds for USUV screening at national reference laboratories. We necropsied the bird specimens and screened them for USUV-specific RNA. During August 2011-November 2015, a total of 230 specimens of 15 species ( $85.7 \%$ common blackbirds) from 132 different sites tested positive for USUV. We used European Land Surface Temperature (EuroLST) dataset maps with 9 bioclimatic variables at $250-\mathrm{m}$ resolution as explanatory variables for the distribution modeling of USUV (27). Bioclimatic variables are derived from monthly temperature and rainfall values. These biologically meaningful variables represent annual trends, seasonality, and extreme or limiting environmental factors.

\section{USUV Distribution Modeling}

We applied an ensemble boosted regression tree (BRT) approach using R software (https://www.r-project.org) with the packages raster, dismo, and ecospat and visualized with ggplot2, which was successfully applied to other mosquitoborne viruses in the past (e.g., Zika virus) (28). We calibrated BRT models with presence-only data and 10,000 random background points selected from the entire area of Germany. To account for the biased bird collection due to the unsystematic dead bird surveillance program and to increase the robustness of model predictions and quantify model uncertainty, we selected 300 random subsamples of the presence data with replacement. Due to locality uncertainties in the presence data (e.g., mobility of the birds and imprecise reporting by the volunteer senders), we applied a random point selection within the corresponding German postal code areas $\left(0.31-891.68 \mathrm{~km}^{2}\right.$, mean size $\left.32.00 \mathrm{~km}^{2}\right)$ for all presence points (i.e., sites with birds testing positive for USUV) in each subsample. In addition, we selected a new set of 10,000 random background points for each model. We weighted background points and occurrence points equally in each of the 300 BRT models, which we averaged for the final USUV distribution map. We converted the continuous distribution map for USUV to a binary map with areas that are suitable or unsuitable for USUV. Following Pigott et al. (29), we selected a threshold that included $90 \%$ of the USUV occurrence points. We chose a threshold cutoff of $90 \%$ instead of $100 \%$ to account for potential spatial inaccuracies of the occurrence point dataset.

We validated the models with a 10 -fold cross-validation approach. We produced a total of 300 random split sampling datasets with 10 subsets for training datasets (comprising $10 \%$ of the presence and background observations) and 10 subsets for test datasets (comprising $90 \%$ of the presence and background observations) each. We used the training datasets to assess the ability of the models to predict the test dataset with the area under the curve (AUC) statistic. We averaged the AUC values of the models across the 10 models of each split sampling dataset and finally across the 300 average AUC values. Furthermore, we applied a pairwise distance sampling procedure to avoid AUC inflation due to spatial sorting bias, which is considered to give a more realistic quantification of the model performance especially regarding its transferability (30).

\section{Bird Population Data}

Bird abundance data were collected within the citizen science program Stunde der Gartenvögel (Hour of the Garden Birds) in Germany. This program is organized by the German BirdLife partner Naturschutzbund Deutschland (Nature and Biodiversity Conservation Union) and its counterpart Landesbund für Vogelschutz in Bayern (Bavarian Society for the Protection of Birds). During the second weekend of May each year, German citizens were requested to count the maximum number of specimens per bird species observed in their gardens in a time frame of 1 hour. We used the data for the 15 most commonly detected bird species, with at least 247,000 observed specimens each during 2006-2016, for further analyses: Eurasian 
blue tit (Cyanistes caeruleus), common chaffinch (Fringilla coelebs), Eurasian magpie (Pica pica), European greenfinch (Chloris chloris), black redstart (Phoenicurus ochruros), great tit (Parus major), common blackbird, house sparrow (Passer domesticus), Eurasian tree sparrow (Passer montanus), common swift (Apus apus), common house martin (Delichon urbicum), carrion crow (Corvus corone), common wood pigeon (Columba palumbus), European robin (Erithacus rubecula), and common starling (Sturnus vulgaris). The dataset consisted of 317,533 unique observation datasets with anonymized sampling locations at the level of postal code regions in Germany, each giving information on the number of specimens per bird species and sampling site.

\section{Bird Population Modeling}

We applied a generalized additive model approach to analyze the population development of each of the 15 bird species. This statistical approach was first developed by Fewster et al. (31) to describe population trends in breeding birds and later successfully used to model bird and bat populations $(32,33)$. We used the GAM framework to fit a single smoothed curve to the trend of the number of bird specimens in the USUV-positive areas and USUV-negative areas per year. In addition, to allow for differences in relative abundances between sites, we included a site term in the models. Following the suggestion by Fewster et al. (31), we set the selection of the degree of smoothing in the GAM to 0.3 times the number of years of the survey data $(\mathrm{df}=3)$.

We avoided the problems of temporal autocorrelation within the abundance data (31) and overdispersion (34) by using a bootstrap approach. We produced CIs around the smoothed trends with a total of 300 bootstrap samples by resampling with replacement observations from the original dataset for each bird species. We classified each sampling site of the bird population data to be located in the USUV-positive or USUV-negative area on the basis of site coordinates and the USUV binary map. Spatial information of the bird observation sites was available only at the level of postal code regions; therefore, for each bootstrap sample, we took the mean of observed specimens per species within each region and then randomly assigned it within its postal code region to classify it as within the USUV-suitable or USUV-unsuitable area.

We set 2011 as the baseline year (index $=100$ ); this year was the last time bird abundance data were collected before the first epizootic outbreak of USUV in Germany (14). Nonoverlapping 95\% bootstrap CIs with index $=100$ and nonoverlapping $95 \%$ bootstrap CIs between the USUV-suitable areas and USUV-unsuitable areas in 2016 were interpreted as a statistically significant difference $(\mathrm{p}<0.05)$.

\section{Results}

The mean of the ensemble of 300 BRTs indicated the highest probability for USUV circulation in southwestern Germany (Figures 1, 2; online Technical Appendix Figure 1, https://wwwnc.cdc.gov/EID/article/23/12/17-1257Techapp1.pdf). Environmentally suitable areas extended from southwestern Germany at the border with France along the valley of the Upper Rhine toward western Germany. The area represented $9,510 \mathrm{~km}^{2}$ of the country $(2.7 \%)$. The EuroLST bioclimatic variable with the strongest influence on USUV risk was the annual mean temperature, contributing $71.4 \%$ to the variation in the ensemble of models. The next most influential variables were mean temperature of the coldest quarter of the year $(8.9 \%)$, temperature seasonality $(7.2 \%)$, and minimum temperature of the coldest month (5.2\%). The other 5 variables had $<5.0 \%$ effect each on USUV risk: mean temperature of the warmest quarter $(2.8 \%)$, mean diurnal range $(1.6 \%)$, temperature annual range $(1.3 \%)$, maximum temperature of the warmest month $(1.2 \%)$, and isothermality $(0.4 \%)$ (online Technical Appendix Figure 2). With an AUC value of 0.89 ( $\pm 0.08 \mathrm{SD}), 10$ fold cross-validation indicated high predictive power of the BRT ensemble map.

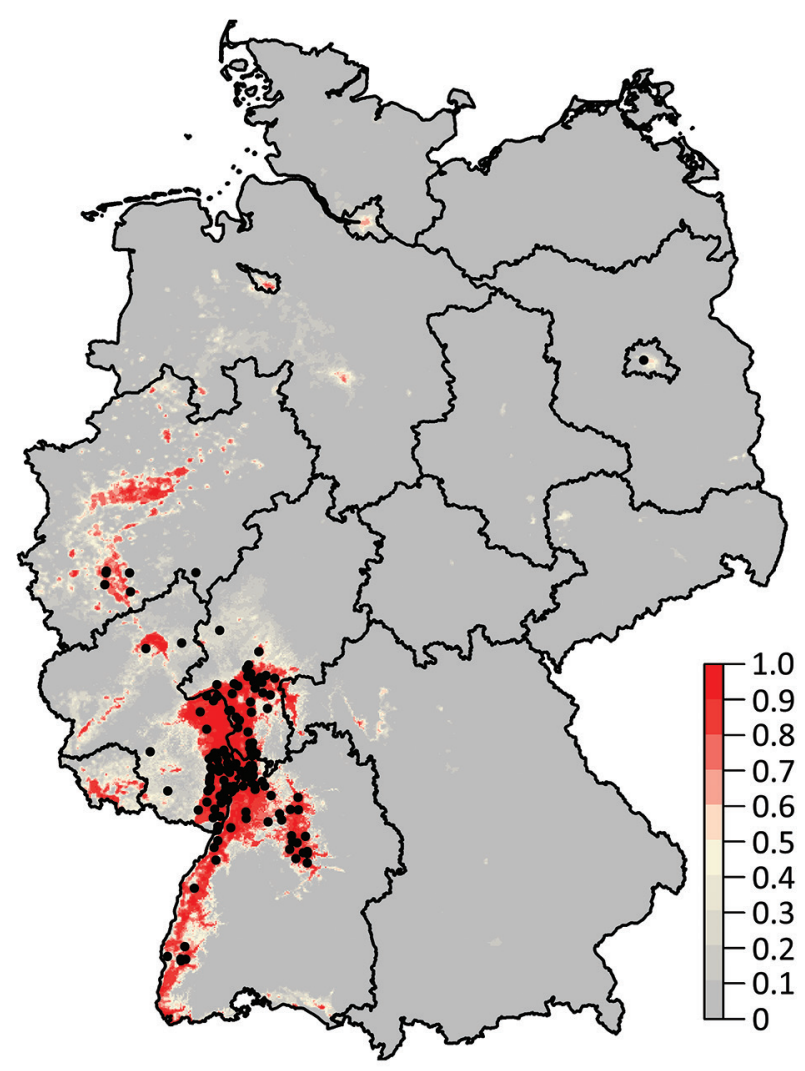

Figure 1. Probability of Usutu virus (USUV) occurrence in Germany derived from 300 boosted regression tree models. Black dots denote sites with dead birds that tested positive for USUV. The color intensity indicates the probability of occurrence of USUV. 
Eleven of 15 bird species analyzed did not show a statistically significant difference in the population development between the areas suitable and unsuitable for USUV since 2011. We determined overlapping 95\% bootstrap CIs between USUV-suitable and USUVunsuitable areas for 2016 (Table; online Technical Appendix Figure 3). Only 4 species had nonoverlapping CIs in 2016 (Table; Figure 3), that is, statistically significant different population indices between both areas. However, the great tit and house sparrow showed higher population indices in the USUV-suitable areas, indicating no negative population impact of USUV. The Eurasian tree sparrow had a statistically significant lower population index in the USUV-suitable area, but the species' populations showed a very sharp positive development in both areas compared with the baseline year 2011. Thus, with a difference of $\approx 15.7 \%$ between the means of population indices in 2016 , only the common blackbird showed both a statistically significant lower population index compared with the baseline year $(\mathrm{CIs}<100)$ and a statistically significant lower population index in the USUV-suitable area compared with the USUV-unsuitable area (nonoverlapping CIs between both areas).

\section{Discussion}

During the past 2 decades, an ongoing spread of USUV and a continuous circulation of the virus after initial establishment have been observed in different countries in Europe $(2,10)$, highlighting the demand to understand the distribution of USUV and its ecosystem effects in the outbreak areas. Due to the enzootic transmission cycle of USUV with birds as amplifying hosts, the question regarding the effect of the virus on avian populations in particular was open. In this study, we compared the population dynamics of 15 common bird species between regions in Germany identified as USUV-suitable and USUV-unsuitable. Previous assessments were particularly limited by the missing explicit spatial distinction between areas with and without circulation of USUV. In addition, these studies did not distinguish population-level impacts of the disease from the natural fluctuations; that is, they did not use long-term bird abundance data that extend before and after the emergence of the first USUV outbreak.

Therefore, in a first step, we applied a distribution modeling approach to identify areas with and without potential circulation of USUV in Germany. The applied modeling approach was previously shown to be suitable to map the distribution of mosquitoborne viruses like dengue virus (35) or Zika virus (28). Potential outbreak areas for USUV were predominantly located in southwestern Germany, where the annual mean temperature was the most influential variable explaining the observed distribution (i.e., the virus showed an increasing probability of occurrence

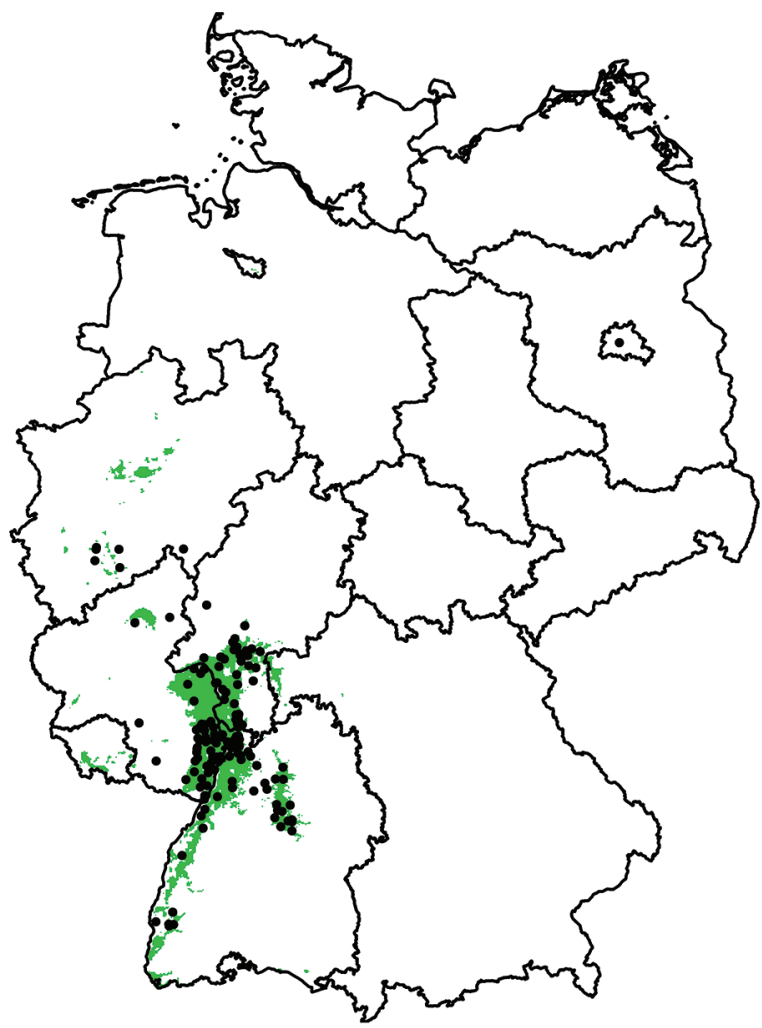

Figure 2. Areas suitable (green) and unsuitable (white) for Usutu virus (USUV) in Germany derived from 300 boosted regression tree models. Black dots denote sites with dead birds detected positive for USUV.

with increasing annual mean temperatures). Although the main transmission parameters of USUV are unknown (e.g., extrinsic incubation period), temperature is probably one of the most important drivers of USUV circulation, because the mosquito vectors are exothermic and the replication rate of the viruses increases as temperature increases. For example, laboratory experiments demonstrated that higher temperatures resulted in higher USUV infection rate of Culex pipiens mosquitoes (36). Nevertheless, although the ensemble of boosted regression tree models had a high performance in the differentiation of areas suitable and unsuitable for USUV in Germany, it should be kept in mind that this estimation has some degree of uncertainty. A high probability of occurrence for USUV does not necessarily mean that the virus ultimately arrives and establishes itself (28). In addition to environmental suitability, different additional parameters influence the spread and circulation of arboviruses, including vector/host mobility or herd immunity $(19,37)$.

Furthermore, the annual dynamics of USUV highly depend on the temporal temperature profile within the course of the year. The high activity of USUV in the late summer and beginning of autumn 2016, for example, was 
Table. Bird population indices by species differentiated USUV-suitable and USUV-unsuitable areas, Germany, $2016^{*}$

\begin{tabular}{|c|c|c|c|}
\hline \multirow[b]{2}{*}{ Species } & \multicolumn{2}{|c|}{ Mean population index, $\%(95 \% \mathrm{Cl})$} & \multirow{2}{*}{$\begin{array}{c}\text { Difference in mean change } \\
\text { between areas, \%† }\end{array}$} \\
\hline & USUV-suitable area & USUV-unsuitable area & \\
\hline Eurasian blue tit (Cyanistes caeruleus) & $115.0(108.3-120.8)$ & $107.5(105.8-108.8)$ & 7.5 \\
\hline Common chaffinch (Fringilla coelebs) & $98.5(93.0-104.4)$ & $93.6(91.8-95.4)$ & 4.9 \\
\hline Eurasian magpie (Pica pica) & $104.1(98.4-109.9)$ & $97.0(95.5-98.4)$ & 7.0 \\
\hline Eurasian tree sparrow (Passer montanus) & $560.8(428.4-760.6)$ & $2,318.7(2,097.0-2,511.5)$ & $-1,757.8$ \\
\hline European greenfinch (Chloris chloris) & $78.2(72.5-83.6)$ & $76.1(74.6-77.4)$ & 2.1 \\
\hline Black redstart (Phoenicurus ochruros) & $49.8(46.0-53.2)$ & $50.4(49.5-51.3)$ & 0.6 \\
\hline Common blackbird (Turdus merula) & $79.7(77.1-82.3)$ & $95.4(94.6-96.2)$ & -15.7 \\
\hline House sparrow (Passer domesticus) & $100.8(94.0-106.8)$ & $88.7(87.2-90.2)$ & 12.1 \\
\hline Great tit (Parus major) & $114.5(108.6-120.2)$ & $105.5(104.1-106.8)$ & 9.0 \\
\hline Common swift (Apus apus) & $67.7(59.6-76.7)$ & $73.2(70.9-75.9)$ & -5.6 \\
\hline Common house martin (Delichon urbicum) & $74.8(66.8-83.1)$ & $73.9(71.4-76.5)$ & 0.9 \\
\hline Carrion crow (Corvus corone) & $129.8(107.4-155.2)$ & $119.3(113.8-123.6)$ & 10.5 \\
\hline Common wood pigeon (Columba palumbus) & $191.4(172.2-212.6)$ & $175.0(170.6-180.0)$ & 16.5 \\
\hline European robin (Erithacus rubecula) & $101.1(94.5-108.0)$ & $97.8(95.9-99.5)$ & 3.3 \\
\hline Common starling (Sturnus vulgaris) & $106.9(98.9-115.1)$ & $115.8(112.8-118.9)$ & -8.8 \\
\hline
\end{tabular}

linked to temperature anomalies in September; significant positive deviation from the 30-year mean temperatures will have shortened the extrinsic incubation period and, at the same time, potentially caused increased vector abundance and associated vector-host contact rate $(12,19)$.

We observed a statistically significant stronger decline of the population in the USUV outbreak areas compared with the USUV-unsuitable area was observed only for the common blackbird and not for any other analyzed bird taxa, including species regularly tested positive for USUV in Europe (e.g., house sparrow and common starling) (2). This finding is in contrast to other mosquitoborne avian viruses, which often show negative effects on the populations of several bird species at the same time; WNV in North America negatively affected the populations of $\geq 7$ bird species, leading to population reduction of up to $45 \%$ (15), and avian malaria parasites potentially caused the extinction of several bird taxa in Hawaii, USA (10). One possible explanation might be that population declines of some species are masked by natural population dynamics or spatial-temporal variability of the population fluctuations (15), such as those caused by largely neglected bird pathogens like polyomaviruses (38). Nevertheless, although USUV can infect $>30$ bird taxa, blackbirds are generally by far the most frequently affected species, comprising $>60 \%$ of all bird specimens testing positive for USUV in Europe (2). The underlying causes of a remarkably higher frequency of USUV-positive common blackbirds compared with other bird species are unknown, but some factors may include the wide distribution and abundance of the species (39), its conspicuous size and color, and its close association with humans (40), all of which might contribute to the high recovery rate of blackbird bodies. Potential reasons for a higher sensitivity to USUV might be a higher virus susceptibility (41), behavioral traits (42), or different spatial-temporal distribution in relation to the vector/virus distribution (43).

During the USUV outbreak in Germany, the common blackbird population decreased by an additional $15.7 \%$ in the USUV-suitable area compared with the USUVunsuitable area. Thus, assuming a mean density of 111.93 birds $/ \mathrm{km}^{2}$ ( 8 million breeding pairs each having approximately 3 fledglings per year [44] and a USUVsuitable area of $\left.9,510 \mathrm{~km}^{2}\right), \geq 167,119$ birds died due to USUV since 2011; this estimate does not include other population effects like immigration compensating a part of the USUV-related population decline. The estimate is substantially higher than the one determined in the study by Bosch et al. (21), assuming 40,000 common blackbird deaths in the USUV outbreak in Germany in 2011-2012, which did not account for persistent USUV-related deaths. At the same time, the overall population decline of the common blackbird is considerably smaller than $50 \%-90 \%$ $(22,23)$, which might reflect only the short-term population declines. Nevertheless, several studies reported local extinction of common blackbirds probably caused by the USUV outbreak $(18,21,22)$, which can be explained by local high virus transmission (e.g., favorable distribution of vectors and hosts). A relatively large spatial heterogeneity of the impact of mosquitoborne viruses on bird populations was also observed for WNV in North America (15); that rate is potentially related to the connection between the local vector and the bird community and influenced by land use and climate parameters (43).

USUV activity after the first outbreak in Germany in 2011-2012 was remarkably lower in the following years, as reflected in the detection of fewer USUV-positive dead birds $(25,26)$. However, the common blackbird population in the USUV-suitable areas continued to decline after the initial outbreak. A similar observation was made for WNV 

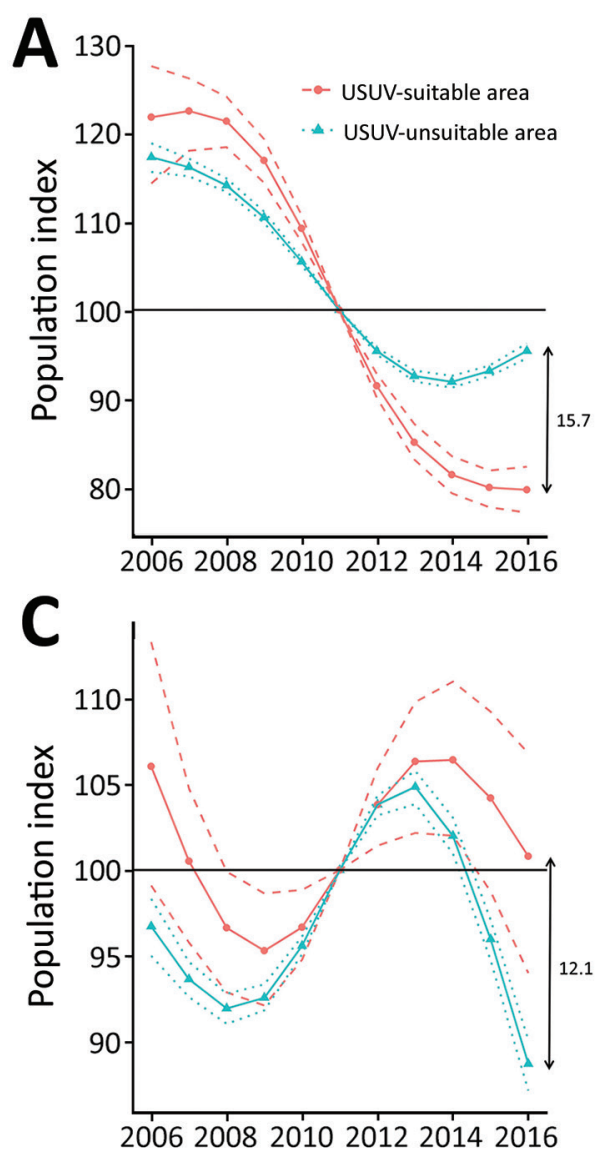
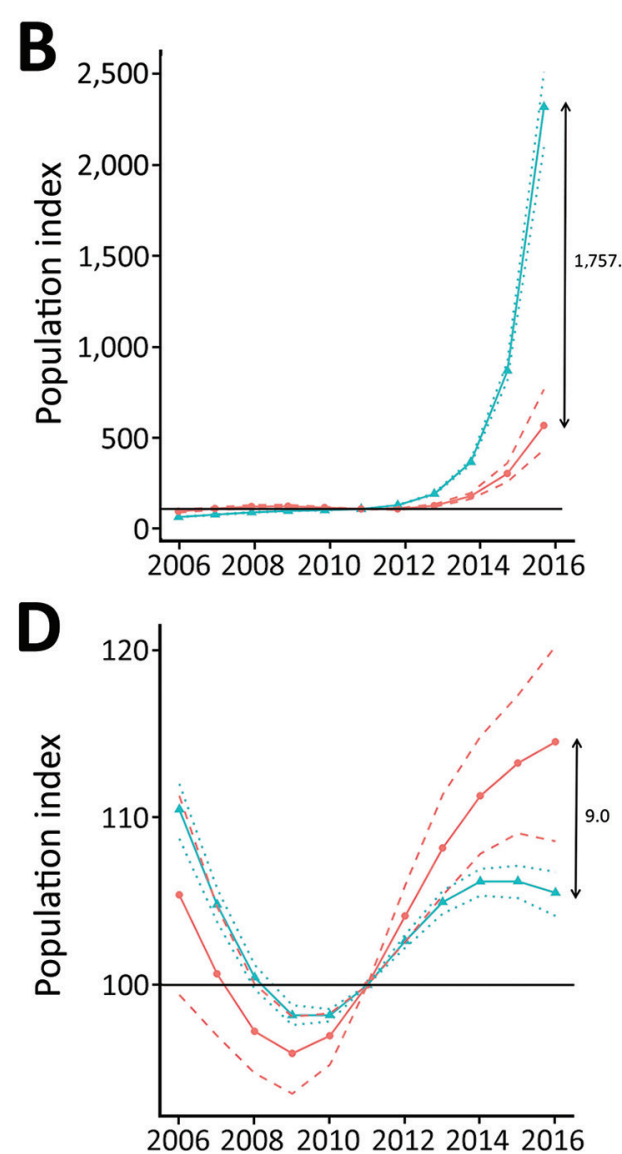

Figure 3. Index curves of the generalized additive model (GAM) approach with 300 bootstraps for breeding bird survey data of 4 bird species for Usutu virus (USUV)-suitable and USUV-unsuitable areas in Germany, 2016. A) Common blackbird; B) Eurasian tree sparrow; C) house sparrow; D) great tit. Solid lines indicate the mean indices from a GAM with $3 \mathrm{df}$; dashed/dotted lines represent nonoverlapping 95\% bootstrap Cls. The horizontal line indicates the baseline year 2011 (index $=100$ ), which is the last time point when bird abundance data were collected before the first known epizootic outbreak of USUV in Germany. Double arrows indicate the difference between the mean index curves for 2016. in North America, which has a persistent impact for different bird species resulting in a lower survival rate without signs of recovery after the first outbreak of the virus (45). Therefore, due to the ongoing and widespread circulation of USUV in Central Europe (12), we must expect a longterm decline of common blackbird populations in areas with USUV occurrence, leading to a substantial alteration of the bird communities in the European USUV outbreak areas.

We still lack comprehensive data on the interaction between USUV and its vectors, hosts, and environmental parameters. We need data on the avian hosts to clarify the epidemiology of USUV and investigation into ecologic consequences, especially if they increase the risk of infection for humans. For example, the high mortality rate among common blackbirds might increase the chance of USUV spillover to humans, because the dead hosts are not present as immune or dead-end hosts $(15,43,46,47)$. In addition, although no USUV effect was found for bird species classified as threatened (e.g., common starling) (48), a wide variety of bird species may be susceptible to USUV infections (2). Therefore, further studies should also focus on bird species not covered by the bird abundance dataset used here, such as wetland birds, which occupy areas that generally harbor high numbers of mosquitoes (49).
In summary, USUV had a statistically significant negative impact on the population of common blackbirds in suitable areas in Germany: a lower population index compared with the baseline year (CIs <100) and a statistically significant lower population index in the USUV-suitable area compared with the USUV-unsuitable area (nonoverlapping CIs between both areas). We observed no significant effect for the other 14 bird species included in the study. Five years after the first detection of USUV in southwest Germany, the circulation of the virus resulted in an additional decline of $\approx 15.7 \%$ in the common blackbird populations compared with the development of populations not affected by USUV. Avian populations are under different threats, including changes of land use and climate change $(15,24)$. The emergence of USUV in Europe is a further threat that can cause substantial changes in ecosystem services provided by birds, such as seed dispersal (50). The recent outbreak of USUV in 4 Central European countries (Germany, Netherlands, Belgium, and France) underlines the largescale distribution of USUV spanning from southern to central Europe $(2,12)$. In conclusion, USUV could affect bird populations, at least common blackbirds, across Europe. 


\section{Acknowledgments}

We thank Heike Baum and Alexandra Bialonski for assistance in the laboratory work.

This work was financially supported by the German Federal Ministry of Food and Agriculture (BMEL) through the Federal Office for Agriculture and Food (BLE), grant no. 2819104315.

Dr. Lühken is a researcher at the Bernhard Nocht Institute for Tropical Medicine, World Health Organization Collaborating Centre for Arbovirus and Hemorrhagic Fever Reference and Research, Hamburg, Germany. His main research focus is the spatiotemporal distribution of vectors and associated pathogens.

\section{References}

1. De Madrid AT, Porterfield JS. The flaviviruses (group B arboviruses): a cross-neutralization study. J Gen Virol. 1974; 23:91-6. http://dx.doi.org/10.1099/0022-1317-23-1-91

2. Nikolay B. A review of West Nile and Usutu virus co-circulation in Europe: how much do transmission cycles overlap? Trans R Soc Trop Med Hyg. 2015;109:609-18. http://dx.doi.org/10.1093/trstmh/ trv066

3. Barbic L, Vilibic-Cavlek T, Listes E, Stevanovic V, Gjenero-Margan I, Ljubin-Sternak S, et al. Demonstration of Usutu virus antibodies in horses, Croatia. Vector Borne Zoonotic Dis. 2013;13:772-4. http://dx.doi.org/10.1089/vbz.2012.1236

4. Cadar D, Maier P, Müller S, Kress J, Chudy M, Bialonski A, et al. Blood donor screening for West Nile virus (WNV) revealed acute Usutu virus (USUV) infection, Germany, September 2016. Euro Surveill. 2017;22:30501. http://dx.doi.org/10.2807/1560-7917. ES.2017.22.14.30501

5. Cadar D, Becker N, Campos RM, Börstler J, Jöst H, Schmidt-Chanasit J. Usutu virus in bats, Germany, 2013. Emerg Infect Dis. 2014;20:1771-3. http://dx.doi.org/10.3201/ eid2010.140909

6. Allering L, Jöst H, Emmerich P, Günther S, Lattwein E, Schmidt M, et al. Detection of Usutu virus infection in a healthy blood donor from south-west Germany, 2012. Euro Surveill. 2012; 17:20341.

7. Vilibic-Cavlek T, Kaic B, Barbic L, Pem-Novosel I, Slavic-Vrzic V, Lesnikar V, et al. First evidence of simultaneous occurrence of West Nile virus and Usutu virus neuroinvasive disease in humans in Croatia during the 2013 outbreak. Infection. 2014;42:689-95. http://dx.doi.org/10.1007/s15010-014-0625-1

8. Calzolari M, Bonilauri P, Bellini R, Albieri A, Defilippo F, Maioli G, et al. Evidence of simultaneous circulation of West Nile and Usutu viruses in mosquitoes sampled in Emilia-Romagna region (Italy) in 2009. PLoS One. 2010;5:e14324. http://dx.doi.org/ 10.1371/journal.pone.0014324

9. Grottola A, Marcacci M, Tagliazucchi S, Gennari W, Di Gennaro A, Orsini M, et al. Usutu virus infections in humans: a retrospective analysis in the municipality of Modena, Italy. Clin Microbiol Infect. 2017;23:33-7. http://dx.doi.org/10.1016/j.cmi.2016.09.019

10. Engel D, Jöst H, Wink M, Börstler J, Bosch S, Garigliany M-M, et al. Reconstruction of the Evolutionary history and dispersal of Usutu virus, a neglected emerging arbovirus in Europe and Africa. MBio. 2016;7:e01938-15. http://dx.doi.org/10.1128/ mBio.01938-15

11. Weissenböck H, Bakonyi T, Rossi G, Mani P, Nowotny N. Usutu virus, Italy, 1996. Emerg Infect Dis. 2013;19:274-7. http://dx.doi.org/10.3201/eid1902.121191

12. Cadar D, Lühken R, van der Jeugd H, Garigliany M, Ziegler U, Keller M, et al. Widespread activity of multiple lineages of Usutu virus, western Europe, 2016. Euro Surveill. 2017;22:30452. http://dx.doi.org/10.2807/1560-7917.ES.2017.22.4.30452

13. Jöst H, Bialonski A, Maus D, Sambri V, Eiden M, Groschup MH, et al. Isolation of Usutu virus in Germany. Am J Trop Med Hyg. 2011;85:551-3. http://dx.doi.org/10.4269/ajtmh.2011.11-0248

14. Becker N, Jöst H, Ziegler U, Eiden M, Höper D, Emmerich P, et al. Epizootic emergence of Usutu virus in wild and captive birds in Germany. PLoS One. 2012;7:e32604. http://dx.doi.org/10.1371/ journal.pone.0032604

15. LaDeau SL, Kilpatrick AM, Marra PP. West Nile virus emergence and large-scale declines of North American bird populations. Nature. 2007;447:710-3. http://dx.doi.org/10.1038/nature05829

16. van Riper C III, van Riper SG, Goff ML, Laird M. The epizootiology and ecological significance of malaria in Hawaiian land birds. Ecol Monogr. 1986;56:327-44. http://dx.doi.org/ $10.2307 / 1942550$

17. Savini G, Monaco F, Terregino C, Di Gennaro A, Bano L, Pinoni $\mathrm{C}$, et al. Usutu virus in Italy: an emergence or a silent infection? Vet Microbiol. 2011;151:264-74. http://dx.doi.org/ 10.1016/j.vetmic.2011.03.036

18. Steiner HM, Holzer T. Small-scaled differences in the period and extent of population decline in Viennese common blackbirds (Turdus merula L.) after the emergence of Usutu virus [in German]. Vogelwarte. 2008;46:25-35.

19. Rubel F, Brugger K, Hantel M, Chvala-Mannsberger S, Bakonyi T, Weissenböck H, et al. Explaining Usutu virus dynamics in Austria: model development and calibration. Prev Vet Med. 2008;85:16686. http://dx.doi.org/10.1016/j.prevetmed.2008.01.006

20. Chvala S, Bakonyi T, Bukovsky C, Meister T, Brugger K, Rubel F, et al. Monitoring of Usutu virus activity and spread by using dead bird surveillance in Austria, 2003-2005. Vet Microbiol. 2007;122:237-45. http://dx.doi.org/10.1016/j.vetmic.2007.01.029

21. Bosch S, Schmidt-Chanasit J, Fiedler W. Usutu virus as cause of mass mortality in blackbirds Turdus merula and other bird species in Europe: experiences from five outbreaks between 2001 and 2011 [in German]. Vogelwarte. 2012;50:109-22.

22. Konrad A. Usutu virus associated population decline of common blackbirds in the northern Upper Rhine Plain in the summer 2011 [in German]. Avifauna-Nordbad. 2011;42.

23. Tietze D, Lachmann L, Wink M. Does the Hour of the Garden Birds capture recent trends? [in German]. Vogelwarte. 2014;52:258-9.

24. Sauerbrei R, Aue B, Krippes C, Diehl E, Wolters V. Bioenergy and biodiversity: Intensified biomass extraction from hedges impairs habitat conditions for birds. J Environ Manage. 2017;187:311-9. http://dx.doi.org/10.1016/j.jenvman.2016.11.052

25. Ziegler U, Jöst H, Müller K, Fischer D, Rinder M, Tietze DT, et al. Epidemic spread of Usutu virus in southwest Germany in 2011 to 2013 and monitoring of wild birds for Usutu and West Nile viruses. Vector Borne Zoonotic Dis. 2015;15:481-8. http://dx.doi.org/10.1089/vbz.2014.1746

26. Ziegler U, Fast C, Eiden M, Bock S, Schulze C, Hoeper D, et al. Evidence for an independent third Usutu virus introduction into Germany. Vet Microbiol. 2016;192:60-6. http://dx.doi.org/ 10.1016/j.vetmic.2016.06.007

27. Metz M, Rocchini D, Neteler M. Surface temperatures at the continental scale: tracking changes with remote sensing at unprecedented detail. Remote Sens. 2014;6:3822-40. http://dx.doi.org/10.3390/rs6053822

28. Messina JP, Kraemer MU, Brady OJ, Pigott DM, Shearer FM, Weiss DJ, et al. Mapping global environmental suitability for Zika virus. eLife. 2016;5:e15272. http://dx.doi.org/10.7554/ eLife. 15272

29. Pigott DM, Golding N, Mylne A, Huang Z, Henry AJ, Weiss DJ, et al. Mapping the zoonotic niche of Ebola virus disease in Africa. eLife. 2014;3:e04395. http://dx.doi.org/10.7554/eLife.04395 
30. Wenger SJ, Olden JD. Assessing transferability of ecological models: an underappreciated aspect of statistical validation. Methods Ecol Evol. 2012;3:260-7. http://dx.doi.org/10.1111/ j.2041-210X.2011.00170.x

31. Fewster RM, Buckland ST, Siriwardena GM, Baillie SR, Wilson JD. Analysis of population trends for farmland birds using generalized additive models. Ecology. 2000;81:1970-84. http://dx.doi.org/10.1890/0012-9658(2000)081[1970: AOPTFF]2.0.CO;2

32. Barlow KE, Briggs PA, Haysom KA, Hutson AM, Lechiara NL, Racey PA, et al. Citizen science reveals trends in bat populations: the National Bat Monitoring Programme in Great Britain. Biol Conserv. 2015;182:14-26. http://dx.doi.org/10.1016/ j.biocon.2014.11.022

33. Roche N, Langton S, Aughney T, Russ JM, Marnell F, Lynn D, et al. A car-based monitoring method reveals new information on bat populations and distributions in Ireland. Anim Conserv. 2011;14:642-51. http://dx.doi.org/10.1111/j.1469-1795.2011.00470.x

34. Zuur AF, Ieno EN, Walker N, Saveliev AA, Smith GM. Mixed effects models and extensions in ecology with R. 1st ed. New York: Springer; 2009.

35. Bhatt S, Gething PW, Brady OJ, Messina JP, Farlow AW, Moyes CL, et al. The global distribution and burden of dengue. Nature. 2013;496:504-7. http://dx.doi.org/10.1038/nature12060

36. Fros JJ, Miesen P, Vogels CB, Gaibani P, Sambri V, Martina BE, et al. Comparative Usutu and West Nile virus transmission potential by local Culex pipiens mosquitoes in north-western Europe. One Health. 2015;1:31-6. http://dx.doi.org/10.1016/ j.onehlt.2015.08.002

37. Stoddard ST, Forshey BM, Morrison AC, Paz-Soldan VA, Vazquez-Prokopec GM, Astete H, et al. House-to-house human movement drives dengue virus transmission. Proc Natl Acad Sci U S A. 2013;110:994-9. http://dx.doi.org/10.1073/pnas.1213349110

38. Bert E, Tomassone L, Peccati C, Navarrete MG, Sola SC. Detection of beak and feather disease virus (BFDV) and avian polyomavirus (APV) DNA in psittacine birds in Italy. J Vet Med B Infect Dis Vet Public Health. 2005;52:64-8. http://dx.doi.org/10.1111/ j.1439-0450.2005.00823.x

39. Hagemeijer WJM, Blair MJ, editors. The EBCC atlas of European breeding birds - their distribution and abundance. London: T \& A D Poyser; 1997.

40. Glutz von Blotzheim UN, Bauer KM. Handbook of the birds of Central Europe [in German]. Wiesbaden: Aula-Verlag; 1988.
41. Pérez-Ramírez E, Llorente F, Jiménez-Clavero MÁ. Experimental infections of wild birds with West Nile virus. Viruses. 2014;6:75281. http://dx.doi.org/10.3390/v6020752

42. Ward MP, Raim A, Yaremych-Hamer S, Lampman R, Novak RJ. Does the roosting behavior of birds affect transmission dynamics of West Nile virus? Am J Trop Med Hyg. 2006;75:350-5.

43. Kilpatrick AM, Kramer LD, Jones MJ, Marra PP, Daszak P. West Nile virus epidemics in North America are driven by shifts in mosquito feeding behavior. PLoS Biol. 2006;4:e82. http://dx.doi.org/10.1371/journal.pbio.0040082

44. Gedeon K, Grüneberg A, Mitschke A, Sudfeldt C, Eickhorst W, Fischer S, et al. Atlas Deutscher Brutvogelarten - atlas of German breeding birds [in German with English summaries]. Muenster (Germany): Dachverband Deutscher Avifaunisten, 2014.

45. George TL, Harrigan RJ, LaManna JA, DeSante DF, Saracco JF, Smith TB. Persistent impacts of West Nile virus on North American bird populations. Proc Natl Acad Sci U S A. 2015;112:14290-4. http://dx.doi.org/10.1073/pnas.1507747112

46. Kilpatrick AM, Kramer LD, Campbell SR, Alleyne EO, Dobson AP, Daszak P. West Nile virus risk assessment and the bridge vector paradigm. Emerg Infect Dis. 2005;11:425-9. http://dx.doi.org/10.3201/eid1103.040364

47. Molaei G, Andreadis TG, Armstrong PM, Anderson JF, Vossbrinck CR. Host feeding patterns of Culex mosquitoes and West Nile virus transmission, northeastern United States. Emerg Infect Dis. 2006;12:468-74. http://dx.doi.org/10.3201/eid1203.051004

48. Grüneberg C, Bauer H-G, Haupt H, Hüppop O, Ryslavy T, Südbeck P. Red list of breeding birds in Germany, 5 version, 30 November 2015 [in German]. Berichte Zum Vogelschutz. 2015;52:19-67.

49. Johnson BJ, Munafo K, Shappell L, Tsipoura N, Robson M, Ehrenfeld J, et al. The roles of mosquito and bird communities on the prevalence of West Nile virus in urban wetland and residential habitats. Urban Ecosyst. 2012;15:513-31. http://dx.doi.org/10.1007/s11252-012-0248-1

50. Whelan CJ, Wenny DG, Marquis RJ. Ecosystem services provided by birds. Ann N Y Acad Sci. 2008;1134:25-60. http://dx.doi.org/10.1196/annals.1439.003

Address for correspondence: Renke Lühken, Bernhard Nocht Institute for Tropical Medicine, Bernhard-Nocht-Str. 74, 20359 Hamburg, Germany; email: renkeluhken@gmail.com

\title{
PubMed \\ Centra
}

PublMed

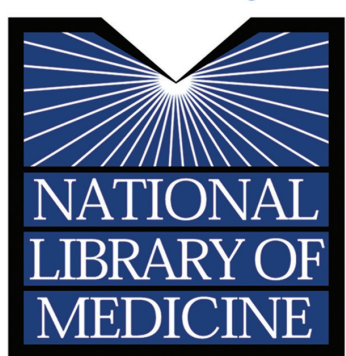

Find Emerging Infectious Diseases content in the digital archives of the National Library of Medicine

\author{
www.pubmedcentral.nih.gov
}

